\section{Urinary sludge caused by ceftriaxone in a young boy}

\author{
Takahisa Kimata, ${ }^{1}$ Kazunari Kaneko, ${ }^{1}$ \\ Masaya Takahashi, 1 Sohsaku \\ Yamanouchi,1 Shoji Tsuji,1 Minoru Kino² \\ 1Department of Pediatrics, Kansai \\ Medical University, ${ }^{2}$ Nakano Children's \\ Hospital, Osaka, Japan
}

\begin{abstract}
It is known that ceftriaxone administration is associated with biliary pseudolithiasis, although the development of urolithiasis has been rarely reported. We encountered a young male with bacterial meningitis complicated by urinary precipitates composed of ceftriaxonecalcium salt which is confirmed by high-performance liquid chromatography. This patient suggested that ceftriaxone significantly increased urinary excretion of calcium, which may be linked to ceftriaxone-related urolithiasis or sludge. It is therefore worthwhile to monitor the levels of urinary calcium to creatinine ratio in patients on ceftriaxone, as they may be at greater risk for developing large stones and renal damage.
\end{abstract}

\section{Introduction}

Ceftriaxone is a third generation cephalosporin, and is a broad spectrum antibiotic with a long plasma half-life that is widely used to treat infections during childhood. ${ }^{1}$ It is well known that ceftriaxone administration has been associated with biliary pseudolithiasis in children.2,3 Although the development of urolithiasis or sludge in the urinary tract has been thought to be rare, 1,4 recent observations have revealed its prevalence is higher than previously thought.5,6 Despite several trials, the mechanism(s) underlying the formation of ceftriaxone-associated urolithiasis remain unclear.5,6

We here report a young male with bacterial meningitis complicated by urinary precipitates composed of ceftriaxone-calcium salt.

\section{Case Report}

A 1-year-old male was admitted to Nakano Children's Hospital, Osaka, Japan with fever and convulsions on October 16, 2008. He had previously been in good health. During a physical examination, it was found that his weight was $10.6 \mathrm{~kg}(+1 \mathrm{SD})$; height, $74 \mathrm{~cm}$ (-0.5SD); pulse rate, $150 / \mathrm{min}$; fever, $39.1^{\circ} \mathrm{C}$; he was conscious; and no neck stiffness was detected. From these findings, the diagnosis of complex febrile seizures was made. However, disturbed consciousness and a stiff neck which developed on the following day prompted us to exam his cerebrospinal fluid. His leukocyte count was $2914 / \mathrm{mm}^{3}$ ( $84 \%$ neutrophil leukocyte); protein, $132 \mathrm{mg} / \mathrm{dL}$; glucose, $5 \mathrm{mg} / \mathrm{dL}$; and simultaneous serum glucose, $119 \mathrm{mg} / \mathrm{dL}$. Gram negative bacilli were detected on cerebrospinal fluid Gram staining. Therefore, a provisional diagnosis of acute bacterial meningitis was made. As shown in Figure 1, both ceftriaxone (120 mg/kg per day) and meropenem (120 $\mathrm{mg} / \mathrm{kg}$ per day) were administered in two equal intravenous doses over $60 \mathrm{~min}$. Adjunctive dexamethasone was also given intravenously every 6 hours at a dose of $0.15 \mathrm{mg} / \mathrm{kg}$ for 4 days. Haemophilus influenzae tybe b grew on cererospinal fluid culture and hemoculture.

On the $13^{\text {th }}$ day of ceftriaxone therapy, the patient produced white turbid urine (Figure 2). However, he did not complain of abdominal pain, there was no dysuria, and his physical examination was unremarkable. Abdominal ultrasonography revealed no abnormal findings. While his serum calcium level was normal $(9.6 \mathrm{mg} / \mathrm{dL})$, his urinary calcium to creatinine ratio $(\mathrm{uCa} / \mathrm{Cr})$ was as high at 0.97 (normal for age: 0.60$){ }^{7}$

Based on these findings, we considered that the white turbid urine was ceftriaxone-calcium precipitates caused by the administered ceftriaxone, which was later confirmed by high-performance liquid chromatography. Therefore, ceftriaxone therapy was discontinued. After discontinuation, no further white turbidity of the urine was noted, and the

$\mathrm{uCa} / \mathrm{Cr}$ gradually normalized in parallel with the recovery from bacterial meningitis, as shown in Figure 1. The patient was discharged without any sequelae on November $20^{\text {th }}$.

\section{Discussion}

Ceftriaxone is primarily eliminated by the kidneys, although in individual patients up to $65 \%$ may be excreted unmetabolized into the bile. ${ }^{1}$ As an anion, ceftriaxone readily forms an insoluble salt with calcium in a 1:1 molar ratio that is capable of precipitation once the solubility of the salt is exceeded. 8 These biochemi-

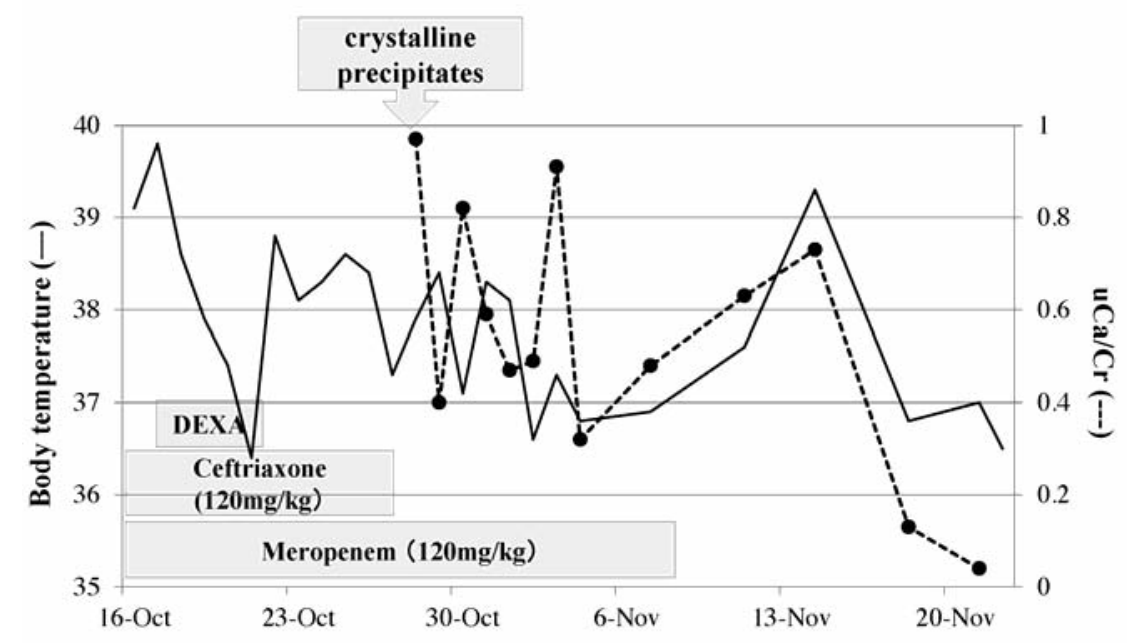

Figure 1. The clinical course of the index case with bacterial meningitis. The solid line and dashed line denote the body temperature and urinary calcium excretion, respectively. $\mathrm{uCa} / \mathrm{Cr}$, urinary calcium to creatinine ratio; DEXA, dexamethasone. 


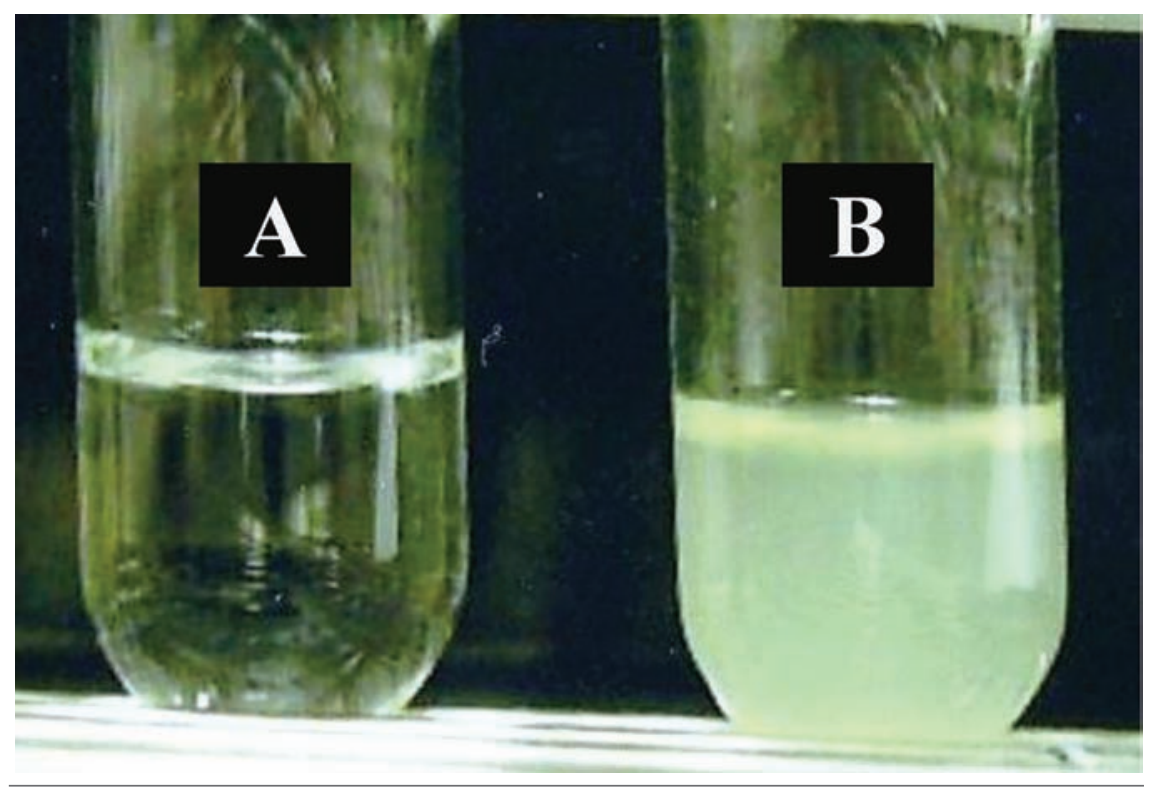

Figure 2. A photograph of the white turbid urine excreted after 13 days of ceftriaxone therapy. The urinary crystalline precipitates shown were confirmed to be ceftriaxone-calcium precipitates. The subject's serum calcium level was normal $(9.6 \mathrm{mg} / \mathrm{dL})$, while his urinary calcium to creatinine ratio was high at 0.97 (normal for age: $\mathbf{0 . 6 0 3}$ ). A, distilled water for contrast; $B$, patient's urine.

cal characteristics of ceftriaxone treatment frequently cause biliary sludge or pseudolithiasis, and are a well-known side effect in children.2,3 This complication is characterized by asymptomatic biliary changes developing after 2-16 days of treatment and is reversible in most cases. $.^{3,4}, 9$ In contrast to the knowledge about the side effect of psuedolithiasis, the epidemiology and pathophysiology of the formation of ceftriaxone-associated nephrolithiasis is poorly understood, although its incidence has been postulated to be higher than previously thought and it appears that stones can form in the same way in the renal collecting system as in hepato-biliary system. However, most cases of ceftriaxone-induced urolithiasis and/or sludge have occurred in association with higher doses (greater than $100 \mathrm{mg} / \mathrm{kg}$ daily) during extended treatment periods or in the presence of predisposing risk factors for urinary calculi.1,6 A recent study based on the findings of the post-treatment ultrasonography disclosed that $1.4-7.8 \%$ of patients had developed small sized renal calculi while on ceftriaxone, 5,6 although Stojanovic et al. stated that there were only 10 cases of ceftriaxoneinduced nephrolithiasis in children reported as of 2009.10 The precise mechanism(s) underlying the development of ceftriaxone-induced nephrolithiasis or sludge are largely unknown, while our case suggests that ceftriaxone treatment may increase the excretion of calcium into the urine leading to the subsequent precipitation of ceftriaxone with calcium.

In conclusion, we should have high index of suspicion for urolithiasis and monitor the $\mathrm{uCa} / \mathrm{Cr}$ of patients on high-dose and long-term ceftriaxone treatment, as these individuals may be at greater risk for large stones and renal damage.

\section{References}

1. de Moor RA, Egberts AC, Schröder CH. et al. Ceftriaxone-associated nephrolithiasis and biliary pseudolithiasis. Eur J Pediatr 1999;158:975-7.

2. Schaad UB, Suter S, Gianella-Borradori A, et al. A comparison of ceftriaxone and cefuroxime for the treatment of bacterial meningitis in children. N Engl $\mathrm{J}$ Med 1990;322:141-7.

3. Bor 0, Dinleyici EC, Kebapci M, Aydogdu SD. Ceftriaxone-associated biliary sludge and pseudocholelithiasis during childhood: a prospective study. Pediatr Int 2004;46:322-4.

4. Gargollo PC, Barnewolt CE, Diamond DA. Pediatric ceftriaxone nephrolithiasis. J Urol 2005;173:577-8.

5. Mohkam M, Karimi A, Gharib A, et al. Ceftriaxone associated nephrolithiasis: a prospective study in 284 children. Pediatr Nephrol 2007;22:690-4.

6. Avci Z, Koktener A, Uras N, et al. Nephrolithiasis associated with ceftriaxone therapy: a prospective study in 51 children. Arch Dis Child 2004;89:1069-72.

7. Sargent JD, Stukel TA, Kresel J, Klein RZ. Normal values for random urinary calcium to creatinine ratios in infancy. J Pediatr 1993;123:393-7.

8. Cochat P, Cochat N, Jouvenet M, et al. Ceftriaxone-associated nephrolithiasis. Nephrol Dial Transplant 1990;5:974-6.

9. Bonnet JP, Abid L, Dabhar A, et al. Early biliary pseudolithiasis during ceftriaxone therapy for acute pyelonephritis in children: a prospective study in 34 children. Eur J Pediatr Surg 2000;10:368-71.

10. Stojanovic V, Djuric Vijatov G. Nephrolithiasis caused by ceftriaxone in a 3 -year-old child with ureteropelvic junction obstruction. Case Report Med 2009;2009:365962. 